\title{
Alire; um histórico
}

\author{
Philippe Bootz ${ }^{1}$
}

Resumo: Neste texto, Philippe Bootz apresenta uma síntese da história e filiações da poesia eletrônica na França, enfatizando as tendências e o significativo papel da "poesia animada". O autor se concentra na vanguarda do grupo L.A.I.R.E. e da revista Alire, ambos fundados por ele e Tibor Papp em 1988 e 1989, respectivamente. Ainda para esse poeta e pesquisador, a literatura eletrônica também tem uma história própria. Essa história é um objeto de debate e posicionamento dentro de um campo de conhecimento, particularmente francês.

Palavras-chave: poesia eletrônica na França; grupo L.A.I.R.E.; revista Alire.

Abstract: Alire; a History - In this paper, Philippe Bootz retraces the history and affiliations of electronic poetry in France, emphasizing its tendencies and significant role in the diffusion of "animated poetry." The author focuses on the vanguard of the L.A.I.R.E. group and the magazine Alire, which he and Tibor Papp founded in 1988 and 1989, respectively. This poet and researcher considers that electronic literature also has its own story. This story is an object of debate and positioning within a field of knowledge, particularly French.

Keywords: electronic poetry in France; L.A.I.R.E. Group; Alire magazine.

Foi durante meu primeiro encontro com Tibor Papp, em 1988, que surgiu a ideia de criar um grupo vanguardista de poesia digital, assim como uma revista de poesia digital num suporte disco que possibilitasse publicar as obras sob a forma de programas executáveis. Já existia, inclusive, nos Estados Unidos, publicações de poesias digitais, no entanto elas só publicavam textos concebidos pelos programas. Tibor e eu pensávamos que os softwares ${ }^{2}$ são partes constituintes da obra digital e que a publicação exclusivamente dos textos concebidos descaracterizava a percepção da obra e a tornava incompleta.

1 Philippe Bootz foi o pioneiro nos estudos da poesia digital francesa. Algumas de suas produções poéticas e críticas estão publicadas em: Passage. Alire 10 (1996); Bootz (2004; 2001; 2007a; 2010); "(Nota do tradutor).

2 Considerando que a maioria dos termos da informática provém do inglês, com grande parte sendo assimilada à língua portuguesa, e à língua francesa, optou-se nesta tradução por mantê-los sem os destaques gráficos das aspas e do itálico. (N.T.). 
Assim nasceu o grupo L.A.I.R.E. e a revista Alire ${ }^{3}$, cujo nome é o próprio anagrama de L.A.I.R.E. ("Leitura Arte Inovação Pesquisa Escrita"), com a reunião de jovens poetas, todos oriundos ou próximos dos movimentos pós-concretos (espacialismo, poesia sonora, poesia visual): Frédéric Develay, Jean-Marie Dutey, Claude Maillard, Tibor Papp e eu mesmo. A primeira ação do grupo foi criar Alire, apresentada pela primeira vez ao público durante um evento que a Revue Parlée do centro Pompidou consagrou ao nascimento da revista em 16 de janeiro de 1989.

Esse primeiríssimo opus, ${ }^{4}$ de número 0.1 , era um livro objeto que comportava obras impressas, uma fita de áudio, um disquete Atari informático e disquetes para PC 5,1/4. ${ }^{5}$ Foi preciso esperar a publicação, alguns dias depois, do número 1 para que a revista se tornasse realmente eletrônica. Esse número 1 retomou obras para PC do número 0.1 , além de algumas outras, sempre para PC, realizadas pelos membros da L.A.I.R.E. As outras mídias foram retiradas da revista. Os disquetes, contendo apenas as obras, estavam acompanhados de um pequeno livro impresso que representava um editorial.

A publicação das obras programadas e das informações sobre diferentes suportes nos parecia na época uma absoluta necessidade, pois era conveniente marcar a especificidade eletrônica dessa nova poesia que surgia e, sobretudo, não criar confusões a seu respeito. Foi essa confusão que tinha impedido até então a percepção da especificidade da literatura eletrônica, simplesmente porque ela permanecia publicada em livros impressos. Colocar textos impressos em disquetes teria recriado tal conflito sobre o suporte eletrônico. Foi para impor a presença do programa, em particular no momento da execução das obras, durante a sua leitura, que nos recusamos a digitalizar os documentos impressos ou gravar no formato impresso ou em vídeo os resultados criados na tela pelos programas.

Só a partir de 1995, essas exigências foram abandonadas: o mundo cultural tinha evoluído nesse intermédio de tempo e ninguém mais duvidaria da natureza específica

3 Para Philippe Bootz, falar da revista Alire (art, lecture, innovation, recherche, ecriture/"arte, leitura, inovação, pesquisa, escrita", 1988) é apresentar a própria evolução da poesia digital francesa e o conceito de geração como um caso particular de programação, distinguido por duas fases: a do período original de "geração texto" e a do período de "geração de animação". Esses diferentes movimentos estéticos foram criados a partir dos grupos OuLiPo (Ouvroir de Littérature Potentielle/ "Oficina de literatura em potencial", 1960) e A.L.A.M.O. (L'Atelier de Littérature Assistée par la Mathématique et les Ordinateurs/ "Oficina de Literatura Assistida pela Matemática e Informática", 1981), associados com o primeiro período, e o L.A.I.R.E. (Lecture, Art, Innovation, Recherche, Ecriture/ "Leitura, Arte, Inovação, Pesquisa e Escrita", 1988) e o Transitoire Observable ("Trânsito observável, 2003), relacionados com o segundo. Texto completo dispionível em: <http://www.dichtung-digital. org/2012/41/bootz.htm>. Acesso em 1 ago. 2013. (N.T.).

4 Substantivo de origem latina que designa, junto com um número, a obra de um compositor na ordem cronológica da sua composição(N.T.).

5 Fundada em 1972, por Nolan Bushell e Ted Tabney, a Atari é uma empresa de produtos eletrônicos e uma das principais responsáveis pela popularização de videogames, como o jogo Pond. O disquete foi lançado, em 1967, pela IBM, no formato disco de 8 polegadas e 80 KB, mas com uso exclusivo para leitura. Em 1975, o disquete foi aprimorado para o disco 5 e $1 / 4$ polegadas, onde se podia ler e gravar dados. Foi somente no início dos anos 1980, que este dispositivo se popularizou. Na década de 1990, o disquete se tornou obsoleto no mercado da informática, sendo substituído por outras mídias digitais com mais velocidade e capacidade de armazanamento, a exemplo do disquete Zip Drive, o CD-Rom, o DVD e o Pen Drive. Para mais informações, ver: <http://www03.ibm.com/ibm/history/exhibits/701/701_intro.html>. Acesso em: 3 fev. 2013. (N.T.). 
da literatura eletrônica. Ela ainda era muito combatida (sofria grande resistência), mas depois se tornou impossível negá-la. A revista conservou, dessa forma, seu formato original: uma série de disquetes (PC e depois PC e MAC), acompanhada de um livreto impresso e apresentada numa caixa de plástico (Box) até o número 9 (1995). Mas ela evoluiu ao longo desses nove números porque o contexto tecnológico passou por forte evolução.

Descobrimos, em 1990, uma propriedade fundamental do eletrônico, denominada desde então de labilidade: o resultado observável na leitura de um programa em execução não está relacionado apenas ao programa, ele depende também do contexto tecnológico no qual está sendo executado. O contínuo crescimento da potência dos computadores teve como efeito o aumento da velocidade de execução dos programas, o que acabou por descaracterizar a temporalidade das animações e, em alguns casos, por reduzir significativamente a sua legibilidade, sobretudo a partir de 1993.

Essa propriedade não poderia ter sido descoberta naquela época sem a permanência editorial da revista. Aliás, ela não foi descoberta pelos universitários, mas sim por autores. Diversas atitudes estavam à nossa disposição para lidar com essa situação, refletindo conceitos radicalmente diferentes da natureza das obras digitais, "de leitura privada", destinadas a serem lidas no seu material informático. Portanto, esse debate que se instaurou no grupo está bem representado no artigo de Tibor Papp "Littérature sur ordinateur - enregistrement - restitution" ("Literatura no computador - gravação restituição") e nas minhas Notes ("Notas").

Essas duas contribuições foram publicadas no livrete de Alire 3 em 1990. O grupo finalmente aderiu a minha concepção e eu reprogramei, em 1994, o conjunto das obras PC, publicada nos seis números anteriores da revista, integrando um dispositivo de medida e gestão da labilidade que privilegiava a legibilidade das animações em eventual detrimento a outras qualidades estéticas. Essa reprogramação marcou uma mudança editorial da revista que, editada por L.A.I.R.E., em sua versão original, estava na sua segunda edição, e para os demais números que viriam, editada pela associação MOTS-VOIR, da qual sou editor oficial, ${ }^{6}$ mas L.A.I.R.E. permanece no comitê editorial da revista, o que não altera sua linha de edição.

Os três números seguintes (7, 8 e 9) integraram originalmente esse dispositivo que constituiu a segunda edição de Alire e uma atualização em disquete, segundo a nova edição dos números 1 a 6 , que foi gratuitamente enviada para todos os assinantes a revista em 1995. A partir dessa data, esses números foram apenas vendidos sob o formato da segunda edição, todos os exemplares da primeira edição foram retirados de circulação. O resultado disso é que hoje os números da edição original dos seis primeiros números de Alire são extremamente raros, uma vez que ela teve que inventar ao mesmo tempo os "lápis" para escrevê-los, as "páginas" para publicá-los e seus leitores, considerando que o número de exemplares em circulação desses números ainda eram poucos em 1994.

6 Ao lado de Jean-Marie Dutey, Claude Maillard, Tibor Papp. A revista MOTS AVOIR está disponível em: <http:// motsvoir.free.fr/>. Acesso em: 1 ago. 2013. (N.T.). 
Em 1995, o conjunto dos números PC em disquete (1 a 9) da segunda edição está reunido numa publicação única denominada Le salon de lecture életronique ("Salão de leitura eletrônica"). Inicialmente publicado em disquetes, essa produção de leitura foi gravada no mesmo ano em CD-Rom e enriquecida de uma interface que permitisse navegar entre os exemplares por números ou por autor. Ele incluiu também o conteúdo de livretos impressos (tipos de manuais), não sendo acompanhado de nenhum outro documento. Tratava-se, pois, do primeiro CD-Rom francês de poesia eletrônica e certamente um dos mais antigos do mundo. Os exemplares em disquetes restantes não são mais editados, mas permanecem disponíveis para venda na editora. Eles são considerados números de coleção.

O número Alire 10 foi editado, em 1997, conjuntamente com os números 13/14/15/16 da revista DOC(K)S. ${ }^{7}$ O conjunto se apresentava sob a forma de um livro acompanhado de um CD-Rom. Ele estabelecia um panorama representativo dos conceitos da época daquilo que podia ser a poesia eletrônica, comportando 109 contribuições em diferentes formas de apresentação (impressas, fotos, vídeos e programações) de autores dos continentes europeu e americanos (norte e sul). Os números seguintes, 11 a 14, foram publicados em CD-Rom. O último, o número 0.0, é um DVD que marca o fim da revista.

Alire teve um impacto importante no desenvolvimento da poesia eletrônica. Ela possibilitou reagrupar autores, principalmente franceses que, de número em número editado, dialogavam através de suas obras. Uma estética tipicamente francesa, denominada de "estética da frustração", foi se construindo à medida que os seus números iam sendo publicados. Essa estética não colocava o leitor em situações que demonstrassem que as modalidades de leitura estavam inadaptadas a essa nova literatura. Isso aconteceu porque Alire foi criada em uma época onde o público não existia.

Seus autores se sentiam então bem livres para experimentar a não-leitura, uma situação que nenhum editor aceitaria hoje. Alire não é uma empresa editorial, é uma ação militante, um manifesto poético. Ela foi criada por isso, mesmo se as intenções iniciais que Tibor e eu tivemos sobre a revista fossem diferentes: para Tibor, a revista era o órgão editorial de um movimento literário, o local onde podia expressar suas convicções e publicar as suas produções. Do meu lado, eu considerava a revista como uma oportunidade de orientar o desenvolvimento da poesia eletrônica. Considerei como fundamental permitir o desenvolvimento de uma literatura destinada a uma leitura individual, em um quadro privado e íntimo. Ambas as concepções se complementaram, funcionaram. Elas foram mantidas até o fim: nunca procuramos autores ou publicamos obras visando a sua promoção.

Desde 1991, Orlando Carreño, então pesquisador na universidade Complutense de Madri, demonstra em sua tese que Alire é a primeira revista de poesia a publicar programas executáveis. Ela, de fato, atraiu autores estrangeiros. Inicialmente aberta apenas para autores da L.A.I.R.E., ela acolheu, a partir de 1994, autores franceses e depois estrangeiros.

7 Para outras informações sobre a Alire 10 e a revista DOC(K)S, ver o verbete Đ€લ(K)S no texto de Serge Buchardon, Digital Literature in France. Disponível em: < http://dichtung-digital.mewi.unibas.ch/2012/41/bouchardon/ bourchardon.htm >. Acesso em: 1 ago. 2013. (N.T.). 
O número 8 (novembro de 1994) não contém nenhuma obra da L.A.I.R.E., para marcar a abertura da revista. De fato, ela possuia um fundo editorial representativo das tendências dos anos 1990 e do início dos anos 2000.

A maioria dos principais autores de poesia eletrônica, francesa e estrangeira dessa época, publicou na Alire (para citar apenas alguns: Jean-Pierre Balpe, Patrick Burgaud, Philippe Castellin, Annie Abrahams, Reiner Strasser, Eduardo Kac, Jim Rosenberg, John Cayley, Loss Glazier, Jim Andrews, Ladislaõ Pablo Gyori, Wilton Azevedo, Alckmar Luiz dos Santos e Pedro Barbosa) ${ }^{8}$.

Alire não tinha, todavia, vocação para tornar-se uma revista de poesia eletrônica "clássica", é uma das razões pela qual ela nunca foi levada à internet, considerando que as criações poéticas utilizando as especificidades da web não podiam passar por uma revista on-line. É bem o que observamos hoje, as revistas on-line só publicam, massivamente, obras que já poderiam estar em CD-Rom, mesmo se estas fossem escritas numa linguagem feita para a web. Nesse sentido, as revistas Alire 11 e Alire 12 foram concebidas para o formato CD-Rom.

Alire é, portanto, uma revista militante, ligada em particular ao desenvolvimento específico da poesia eletrônica no período que antecedeu a expansão da internet. Ela antecipou certas características que a web tornou familiares, mas que eram desafios nos anos 1980 e 1990: a ideia que a poesia eletrônica fosse destinada para a leitura sobre uma tela de computador e não sobre o papel; que o programa é um elemento fundamental da obra; que ela se dirigesse, como toda poesia, ao leitor no seu quadro privado e não necessariamente destinada a performances públicas, que seu modo de difusão permanecesse no formato da revista.

Também acompanhou a coletiva internacional Transitoire Observable/ "Transição Observável"9 (Alire 12, 2004), participou do renascimento cultural da poesia eletrônica na França, associando-se a outras revistas, certas vezes de grande público, integrando-se a ações pedagógicas nacionais ou exposições. Ela constitui incontestavelmente um ponto de referência na história da poesia eletrônica, mostrando que o impacto cultural de uma produção literária não depende do tamanho do seu público leitor. Como me havia dito Tibor Papp em 1988, não importa muito que uma revista tenha um ou mil leitores, o que conta é que ela exista.

É bom lembrar, nesses tempos onde toda empresa cultural fantasia sobre o tamanho de sua plateia e sobre o slogan de marketing designado como de "grande público". Havia autores que eram e permanecem livres diante desse dogma. Não há dúvida que existam outros hoje, jovens, trilhando certamente caminhos proibidos, impensados ou inomináveis. Pode-se apostar que são eles que constroem a literatura de hoje; a que leremos amanhã.

8 Desses autores estrangeiros, são brasileiros: Eduardo Kac, Wilton Azevedo e Alckmar Luiz dos Santos, o Pedro Barbosa é português. (N.T.).

9 Além de Philippe Bootz eTibor Papp, nesse grupo se destacam Jean-Pierre Balpe, Alexander Gherban, Philippe Castellin, Patrick Burgaud, Érick Serrandour e os artistas Antoine Schmitt, Gérad Giacchi, Xavier Leton e Frédéric Drouillon. Ainda faz parte do Transitoire Observable o poeta Wilton Azevedo, que se juntou ao grupo em 2003. (N.T.). 
Se a existência de Alire pode incentivá-los a seguir seu caminho, então Alire terá plenamente preenchido seu papel, muito além da poesia eletrônica.

Tradução de Reheniglei Rehem

Philippe Bootz é professor de Ciências da Informação e da Comunicação no Departamento de Hipermídias da Université Paris 8 (França), coordenador do grupo Écritures Numériques (Laboratório Paragraphe, UP8), fundador e editor da revista eletrônica Alire (CD-Rom).

philippe.bootz@univ-paris8.fr

Reheniglei Rehem é professora titular de Literatura Brasileira da Universida de Estadual de Santa Cruz (UESC-BA). Possui doutorado em Teoria Literária (UFRJ) e pós-doutorado em TICs-Ciberliteratura (Université Paris 8- França).

r_rehem@yahoo.com.br

\section{Referências}

BOOTZ, P. Alire: a recentless literary investigation. Tradução J. Stevens. Electronic Book Review, n. 9, 1999. Disponível em: <http://www.altx.com/ebr/reviews/rev9/r9boo.htm>. Acesso em: 29/08/2013.

Formalisation d'un modèle fonctionnel de communication à l'aide des technologies numériques appliqué à la création poétique. Paris: Diss. Université de Paris 8, 2001.

"Poésie et informatique", Analyse théorique et réalisation de la partie consacrée à la littérature informatique du. CD-ROM créations poétiques au XX siècle visuelles, sonores, action. CDRP de Grenoble, out/ 2004.

. Les Basiques: La littérature numérique. Leonardo Olats, Collection les Basiques, 2007a. Disponível em: <http://www.olats.org/livresetudes/basiques/litteraturenumerique/basiquesLN.php>. Acesso em: 30/08/2013.

Poetic Machinations. Media Poetry: an International Anthology. Bristol: Intellect Books, $\overline{2007 b}$, p. 213-228.

The Unsatisfied Reading. In: BOOTZ, P.; BALDWIN, S. Regards croisés: Perspectives on

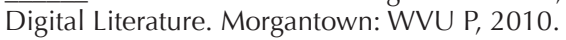

CARREÑO, M.; RODRIGUES O. R. Nuevas Tecnologias de la Informacion y Creacion Literaria. Madrid: Universidad Complutense, 1991.

FUNKHOUSER, C. T. Prehistoric digital poetry: an archaeology of forms, 1959-1995. Tuscaloosa: University of Alabama Press, 2007. 